\title{
THE MANAGEMENT OF CLOSED CHEST INJURIES
}

Douglas Thompson, F.R.C.S.

Baguley Hospital, Manchester 23

On looking into the history of chest trauma and its treatment through the centuries, it is apparent that the chest has been a part of the body that remained, even to the present, ill-understood and its injuries and lesions poorly treated.

From Grecian days up to modern times serious penetrating and other injuries of the chest have resulted, almost without exception, in the death of the injured person with the physician or surgeon standing by helplessly. Medical history was made and recorded whenever a patient with severe chest injury recovered and these cases seemed mostly to be chest wall injuries with lung prolapse.

Pare, that great surgeon of the Renaissance, was one of the first to recognize a traumatic diaphragmatic hernia. He also described a test for a penetrating wound of the lung. His revolutionary treatment of war injuries was well ahead of his time and is much to be admired even today.

The last war saw a major step forward in the understanding and management of chest injuries and yet today, in a society in which chest injury is becoming an increasingly serious problem, the treatment of these patients is often left in the inexperienced hands of junior members of the medical staff who have had little or no instruction in the principles of chest management.

It has been all too frequently the experience of the writer to be asked to see patients, often with relatively mild chest injuries, only to find their condition deteriorating because the principles involved in treatment have not been understood, and it is because of this experience that this paper is presented.

Closed chest injuries only are discussed as they are the most common and because the principles which apply to them also apply to open chest injuries as soon as the opening in the chest is closed.

\section{Classification of Closed Chest Injuries:}

Two major groups are recognized; the dividing line is an arbitrary but useful one-namely the number of ribs fractured.

Group 1.-Three or less ribs injured.

(a) Ribs only fractured.

(b) Ribs fractured and intercostal vessels damaged.

(c) Chest wall and lung damaged.

Group 2.-More than three ribs injured.

(a) Ribs and/or sternum, lungs and mediastinal structures injured.

(b) As in (a) with other organ injury.
These two groups correspond fairly accuratel with the two major traumatic factors responsible for chest injury viz:

\section{Direct Trauma}

Injury is sustained at the site of trauma, e.g. kick in the ribs. Group I injuries usually resu局 from this type of trauma.

\section{Compression Trauma}

In this type of trauma, ribs are bowed and fractured, often in two places. The fractures occur at a site some distance from the point of application of the force. The classical example the steering wheel injury in a car crash. Groug $z$ injuries result, as a rule, from this type of trau

\section{Clinical Features}

The difficulty in classifying the clinical features both symptoms and signs, lies in the gradation of these features which in turn depends upon:

(a) The type and severity of the injury.

(b) The patient's general condition.

(c) The patient's respiratory state.

Symptoms. - The main symptoms are:

Pain.-Mild to severe. In lower thoracic cage injuries upper abdominal pain and rigidit may be caused.

Tightness in the chest.-A more severe symp tom in those with poor respiratory function?

Dyspnoea.

Hamoptysis.-Only if lung is damaged.

Shock.-Not a symptom, but a symptom? complex which may be simulated by hypoxia.

Signs.-The main and more common signs aren.

Reduced movement on injured side and/ok paradoxical movement.

Surgical emphysema-almost invariably pres sent if lung has been damaged. Mediase tinal, and neck emphysema seen if medias@ tinal pleura or mediastinal structures con $=$ taining air have been damaged.

Rapid, laboured breathing-depends largel upon pain and respiratory state. 
Pain and crepitus on chest compression.

Displaced apex beat-usually due to air in pleural cavity and hence away from injured side, thus further embarrassing lung function.

Muffled heart sounds or cracking sounds with mediastinal emphysema.

Normal, hyper-resonant or dull note to percussion, depending upon whether lung is collapsed with fluid or air.

It is absolutely essential to make a thorough physical examination of the pat'ent and if this is not possible immediately because urgent treatment is demanded, then it must be done as soon as the medical situation permits. Other fractures and injury to viscera have been missed by concentrating all attention on the chest. It is also essential that a chest X-ray, both P.A. and lateral if possible, should be taken, in the upright position if the patient's condition will permit it. Failure to do this when facilities are available may be viewed as mismanagement. Physical findings alone cannot be relied upon to exclude a pneumothorax.

A radiological survey of the skeletal bones should also be done if other injury seems at least possible.

\section{Management}

The two major groups will be considered separately but there is much overlapping. In considering the management there is some difficulty in deciding where primary injury ends and complications begin and so to avoid this problem the associated anatomical and physiological disturbances related to the injury are considered as immediate effects and only the long-term effects are viewed as complications.

The object of management is to restore function as rapidly as possible and to achieve this the following aims must be realized:

(a) Counteract the immediate effects.

(b) Assist the body's reaction.

(c) Prevent long-term complications.

The management and complications are presented in tabulated form. Comments on management are made after each table and the treatment of the long term complications which usually involves the employment of thoracic surgical techniques of a specialized nature is stated but not discussed.

\section{Group I Injuries}

Group I (a) (Ribs only)

\begin{tabular}{|c|c|c|c|}
\hline \multirow{2}{*}{ Effects } & \multicolumn{2}{|c|}{ Management } & \multirow{2}{*}{$\begin{array}{l}\text { Compli- } \\
\text { cations }\end{array}$} \\
\hline & Local & General & \\
\hline $\begin{array}{l}\text { Pain } \\
\text { Poor aeration }\end{array}$ & $\begin{array}{l}\text { Strapping } \\
\text { Intercostal nerve block }\end{array}$ & $\begin{array}{l}\text { Analgesics } \\
\text { Physio- }\end{array}$ & Usually \\
\hline $\begin{array}{l}\text { Secretions } \\
\text { Lung collapse }\end{array}$ & Bronchoscopy (rare) & $\begin{array}{l}\text { therapy } \\
\text { Antibiotics }\end{array}$ & none \\
\hline
\end{tabular}

\section{Comments}

(I) Accumulation of secretions leading to collapse of portion of a lung is not a common effect of these simple injuries though may be seen in debilitated and/or emphysematous patients who fail to cough adequately or in those in whom pain is not completely relieved. In these, intercostal nerve block is of great value.

(2) Strapping should be applied to the injured side only from midline anteriorly to midline posteriorly with the patient's chest in expiration. It is not advised that a complete circumferential strapping be applied, particularly to patients with reduced pulmonary function as reducing movement of the uninjured side may embarrass respiration. Its use has become hallowed by convention but there is considerable doubt whether it is of any value in most cases of simple chest injury. Its object is to reduce movement at the ends of the fractured ribs and thus reduce pain, but the patient's own spontaneous reduction in movement usually achieves this and strapping will not relieve the pain of a cough or sneeze. However, occasionally it produces quite dramatic relief and as a first-aid measure is still to be recommended.

(3) Antibiotics generally not needed unless the condition of the patient's chest provides an indication in itself, e.g. purulent bronchial secretions.

\section{Group I (b) (Ribs and Vessels)}

\begin{tabular}{|c|c|c|c|}
\hline \multirow{2}{*}{ Effects } & \multicolumn{2}{|c|}{ Management } & \multirow{2}{*}{$\begin{array}{l}\text { Compli- } \\
\text { cations }\end{array}$} \\
\hline & Local & General & \\
\hline Pain & As in $I(a)$ & As in $1(a)$ & $\begin{array}{l}\text { Constrictive } \\
\text { fibrinous } \\
\text { pleurisy }\end{array}$ \\
\hline Hæmorrhage & $\begin{array}{l}\text { (a) Aspiration } \\
\text { (b) Intercostal tube } \\
\text { drain }\end{array}$ & Replace blood & \\
\hline $\begin{array}{l}\text { Hæmothorax } \\
\text { Lung } \\
\text { collapse }\end{array}$ & (c) Thoracotomy & . & Empyema \\
\hline
\end{tabular}

\section{Comments}

( $\mathrm{I}$ ) The bleeding that occurs in these injuries is from parietal vessels and hence may be severe. If bleeding has stopped and early aspiration is practised, it may be all that is necessary, though intercostal drainage may be required if clot is present and aspiration is not successful. If bleeding is persistent (rising pulse, falling blood pressure and increasing shadow on X-ray), then thoracotomy to identify and control the bleeding is indicated.

(2) If bleeding has been severe enough to cause lung collapse then bronchoscopy is nearly always necessary to clear the bronchi and often is a kinder procedure than persistent attempts to produce coughing which generally will be unsuccessful because the vis-a-tergo needed for expulsion of 
secretions-namely an aerated lung-is not present.

(3) Constrictive fibrinous pleurisy occurs if a hæmothorax has been allowed to organize, especially with a partially collapsed lung. Treatment is thoracotomy and decortication.

(4) Empyema results from infection of a hæmothorax, often, it must be admitted, from frequent or poorly executed aspirations with introduction of infection from without. Treatment is by drainage (intercostal, or by rib resection) and occasionally a decortication later.

\section{Group I (c) (Chest Wall and Lungs)}

\begin{tabular}{|c|c|c|c|}
\hline \multirow{2}{*}{ Effects } & \multicolumn{2}{|c|}{ Management } & \multirow{2}{*}{$\begin{array}{l}\text { Compli- } \\
\text { cations }\end{array}$} \\
\hline & Local & General & \\
\hline $\begin{array}{l}\text { Pain } \\
\text { Hæmorrhage }\end{array}$ & As in I $(b)$ & $\begin{array}{l}\text { Analgesics } \\
\text { Restore blood }\end{array}$ & $\begin{array}{l}\text { Pyopneu- } \\
\text { mothorax }\end{array}$ \\
\hline $\begin{array}{l}\text { Pneumothorax: } \\
\text { (a) Simple }\end{array}$ & $\begin{array}{l}\text { Intercostal tube } \\
\text { drain }\end{array}$ & Antibiotics & \\
\hline (b) Tension & $\begin{array}{l}\text { Emergency-needle } \\
\text { or trocar, then in- } \\
\text { tercostal tube drain }\end{array}$ & $\begin{array}{l}\text { Physio- } \\
\text { therapy }\end{array}$ & \\
\hline $\begin{array}{l}\text { Emphysema: } \\
\text { (a) Parietal }\end{array}$ & $\begin{array}{l}\text { Intercostal tube } \\
\text { drain }\end{array}$ & & \\
\hline (b) Mediastinal & $\begin{array}{l}\text { Suprasternal tube } \\
\text { drain }\end{array}$ & & \\
\hline Lung contusion & $\begin{array}{l}\text { Mild-observe } \\
\text { Severe-tracheos- } \\
\text { tomy. }\end{array}$ & & $\begin{array}{l}\text { Lung } \\
\text { abscess }\end{array}$ \\
\hline Lung laceration & $\begin{array}{l}\text { Mild-intercostal } \\
\text { drain } \\
\text { Severe-thora- } \\
\text { cotomy }\end{array}$ & & \\
\hline
\end{tabular}

\section{Comments}

(I) If a tension pneumothorax has occurredand the patient's rapid respiratory deterioration together with the physical findings of pneumothorax and mediastinal displacement will give the clue to this condition-then a trocar and cannula (preferably) or a wide-bore needle should be inserted immediately to relieve the tension. This should be done after local anæsthetic has been injected unless it is felt that the patient's rapid deterioration contra-indicates further delay. The butt-end of the needle or trocar is controlled with a finger phasing the release of air with expiration. This will allow time for an intercostal tube drain to be prepared and inserted under more favourable conditions.

(2) Surgical emphysema associated with chest injury always means lung damage and often is an indication for the insertion of an intercostal tube to decompress the pneumothorax, and connecting this to an underwater drain. The tube is inserted usually into the second intercostal space anteriorly using local anæsthetic agent. It is advised that sufficient local anæsthetic is present in the syringe so that, on withdrawing the plunger after the needle has been passed through the parietal pleura, air may be observed to bubble through it (a constant flow will confirm a pneumothorax-if few bubbles are obtained which cease rapidly ot usually means lung parenchyma has been entered and another site must be chosen) or blood aspirated into it (to warn of the possibility of major bet displaced mediastinal structures underlying tre site of the proposed insertion of the tube).

(3) If the lung damage is of such severity that adequate suction on the drainage tube cannot keep abreast of the air leak, then severe luofos laceration or bronchial rupture must be considered and if it is thought that this is likely then thoracor tomy is carried out and parenchymal and/ $\overrightarrow{\mathrm{er}}$ bronchial damage sought and repaired. Intes costal tube drainage after this procedure is mas datory.

(4) Mediastinal emphysema usually not severe but may cause embarrassment to the great veins $\frac{t}{\pi}$ if this occurs a suprasternal underwater tube draßg should be inserted.

(5) If lung contusion is severe and especially $\stackrel{\circ}{\mathrm{H}}$ a patient thought or known to have poor respira tory function a tracheostomy may be indicated go assist in adequate aeration. The decision for tracheostomy, however, must be made only aftig all other corrective measures have been carøied

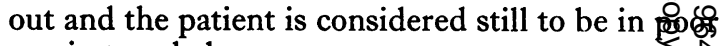
respiratory balance.

(6) A pyopneumothorax is usually the resule inadequate management of a pneumothoras. Satisfactory drainage must be established and lurg. expansion ensured.

(7) Lung abscess may follow infection of $\stackrel{\mathbb{a}}{a}$ contused lung. Conservative management usual $\overrightarrow{\vec{b}}$ is all that is necessary though the danger of at empyema must be born in mind.

(8) Traumatic asphyxia-it is surprising that this is a rare phenomenon in these injuries an hence is not often seen.

\section{Group 2 Injuries}

Although this group has been divided into tw sections, so far as chest management is concernegl they will be considered together.

In most cases serious physiological derangeme has occurred and there is little doubt that some $\overrightarrow{p t}$ these patients die unnecessarily because the severify of the physical and physiological injury has net been recognized and hence treatment has beets started either too late or not at all.

Assuming that there is not a massive blood los or other injury to cause death, these patien deteriorate and die from hypoventilation, the main causes of which are:

Interference with respiratory mechanics-par doxical respiration.

Lung collapse.-(i) Pneumothorax; (ii) Hæm迹 
thorax; (iii) Rupture of diaphragm with abdominal contents in chest.

Severe lung contusion.-(i) Loss of compliance;

(ii) Inadequate diffusion.

Severe pain.

\section{Management}

The management of these more severely injured patients is divided into two stages:

I The urgent reversal of deterioration-in effect first-aid treatment.

2 The longer term maintenance and restoration of physiological function.

\section{Reversal of Deterioration}

This is the critical phase that so often is managed badly and it is this stage that in many hospitals is left in the hands of junior and untrained staff.

The aim is to restore and maintain an adequate oxygen supply. Hence depending upon facilities available:

Establish an adequate airway and give oxygen

(a) Suck out secretions

(b) Insert an intra-tracheal tube

(c) A Brook's airway, or mouth-to-mouth breathing may be called for.

Ensure that the lungs can expand

(a) Needle chest for a pneumothorax and if present allow air to escape, controlling this by finger over butt. Intercostal tube if this is available.

(b) If loose paradoxical segment-this may be stabilized temporarily by:-

(i) Towel clips around rib segment and tension kept on them; or

(ii) Positive pressure respiration by intra-tracheal tube or Ambu resuscitator.

N.B.-Positive pressure respiration is dangerous in presence of an undrained pneumothorax.

Ensure adequate circulating blood volume

(a) Stop any obvious bleeding

(b) Give blood, or plasma expander if blood is not immediately available and loss is severe.

Ensure that other reversible damage is not causing deterioration.

Other mobile fractures or abdominal organ

injury may cause deterioration and should be dealt with once the patients' respiratory and cardiovascular state will permit. It is important to remember that cardiac tamponade or muscle damage may be a cause for a deterioration in circulation.

Make arrangements for transfer to a centre dealing with these injuries if present locally.

\section{Longer Term Maintenance}

This phase is better carried out in a specialized centre though this may not always be present, and hence there seems an urgent need for specialized facilities to be available in all sizeable hospitals where surgeon, physician and anæsthetist can combine in the management of these severely injured patients. As this stage of management is of a more specialized nature, it does not come under the scope of this article but the principles involved will be outlined.

As soon as the patient arrives the following steps are taken:

(a) Immediate bronchoscopy to aspirate and inspect the bronchial tree.

(b) Endotracheal intubation and manual ventilation with oxygen.

(c) X-ray of the chest-P.A. and lateral, and if possible in the upright position.

(d) While this is proceeding the chest is needled for a pneumothorax and if present an intercostal drain inserted if this has not already been done-as stated under emergency treatment, positive pressure respiration in presence of an undrained pneumothorax is dangerous.

(e) Blood for grouping, $\mathrm{PcO}_{2}$, and $\mathrm{Po}_{2}$ is taken-the estimations of these gas values are keystones in the management in these patients.

(f) Tracheostomy is then carried out, if, in the presence of unobstructed ventilation $\mathrm{PCO}_{2}$ is raised and $\mathrm{Po}_{2}$ is lowered. A cuffed tracheostomy tube is used if it is thought that mechanical ventilation is likely to be used.

The patient, now more or less under control, is observed and repeated $\mathrm{PCO}_{2}$ and $\mathrm{Po}_{2}$ estimations are made to assist in the decision about the use of assisted or controlled respiration. It has been accepted for many years that with paradoxical respiration there is a co-and-fro movement of inspired gases between the normal lung and that on the side of the injury. Maloney, Schmutzer and Raschke (I96I) have shown that this 'pendelluft' does not occur and, that on the side of the paradox the lung does expand with inspiration and hence the accumulation of carbon dioxide and reduced oxygen content that may be seen with these injuries is not due to 'stale air' in the lungs.

Hence paradoxical respiration is not in itself an imperative indication either for assisted respiration or surgical fixation of the mobile segment. There has been much discussion (Windsor and Dwyer, I96I; Griffiths, 1961; Sandor, 1963; Virshup, I960) on the relative merits of surgical fixation and so-called lung splinting of the chest wall by conrolled intermittent positive pressure ventilation, and the evidence on balance seems to be in favour of the latter method as the ultimate restoration of 
anatomy and physiological function seems more satisfactory.

This method has been used in those cases in the care of which the writer has been involved. The argument against this method is that these facilities are not available in all hospitals where cases with severe chest injuries may be admitted and this must be accepted. Therefore surgical fixation will still be practised where those patients cannot be transferred to a more specialized unit or where mechanical ventilation is not available.

The indications for surgical fixation or for assisted respiration are:

(a) Hypoventilation in presence of adequate oxygen supply.

(b) Severe pain and/or exhaustion with spontaneous respiration.

(c) Severe deformity of thoracic cage.

Basic steps in management of mechanical ventilation

(a) Take-over by mechanical ventilator achieved by sedating patient.

(b) Further ventilation controlled by $\mathrm{PCO}_{2}$ and $\mathrm{Po}_{2}$ measurements. Patient generally kept slightly over-ventilated.

(c) Gastric intubation-for feeding and to prevent dilatation.

(d) Catheterization (Gibbons catheter) and continuous drainage. (e) Careful aseptic care of tracheostomy wion frequent change of tube and air ke $t$ moist.

( $f$ ) Constant skilled nursing-frequent posturing and physiotherapy-a tippizag bed is essential.

(g) Antibiotic cover.

(h) Regular chest X-rays to check progress

(i) Mechanical ventilation of patient mai tained until:

(i) Chest wall is rigid.

(ii) Patient can maintain normal blo $\overrightarrow{d d}$ $\mathrm{PCO}_{2}$ with spontaneous respirations.

(iii) Patient is completely comfortable without the ventilator.

\section{Summary}

In view of the increasing number of cases $\frac{8}{8} \mathrm{f}$ chest injuries treated in general surgical wardso classification of closed chest injuries is presented.

The clinical features, methods of investigatign and management of the more common types of closed injury are described and a summary of the indications for, and principles in management off, mechanical ventilation is given.

My thanks are due to Mr. W. F. Nicholson, of the Manchester Royal Infirmary, and Dr. T. M. Wilsog, $\overrightarrow{\text { of }}$ Baguley Hospital, for their advice and instruction to preparation of this paper.

\section{REFERENCES}

Barrett, N. R. (1960): Early Treatment of Stove-in Chest, Lancet, i, 293.

BorRIE, J. (1958): 'The Management of Emergencies in Thoracic Surgery'. New York: Appleton-Century-Crofts Iñ Griffiths, H. W. C. (1961): Crush Injuries of the Chest, F. roy. Coll. Surg. Edinb., 6, I3.

Lindskog, G. E. (I96I): Some Historical Aspects of Thoracic Trauma, F. thorac. cardiovasc. Surg., 42, I.

Maloney, J. V., Schmutzer, K. J., and Raschke, E. (196I): Paradoxical Respiration and 'Pendelluft', Ibid., 4r, 29r.ō

SANDOR, F. (1963): Treatment of Stove-in Chest with 'Paradoxical Respiration' in Peripheral Hospitals, Thorax, 18, I 18.

Windsor, H. M., and DwYer, B. (196I): The Crushed Chest, Ibid., 16, 3.

Virshup, M. (I96r): The Anteriorly Crushed Chest or 'Steering-wheel Injury', F. thorac. cardiovasc. Surg., 39, 579. Clinico-Pathological Conference on a Case of Crush Injury of the Chest (1961): Postgrad. med. $\mathscr{7} ., 37,50$ 